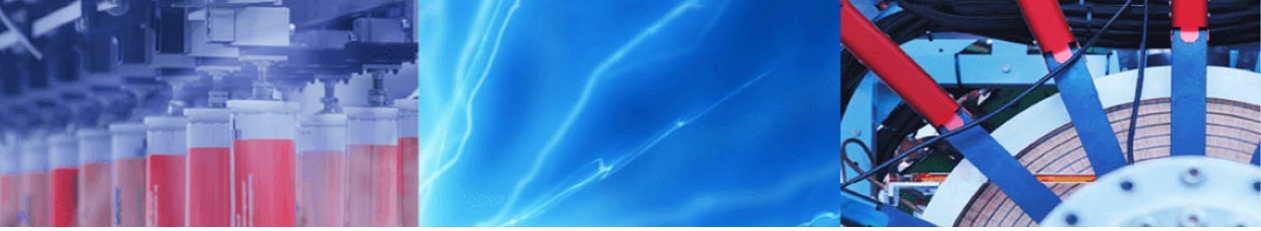

Research Article

\title{
Silicon-based carbonaceous electrocatalysts for oxygen reduction and evolution properties in alkaline conditions
}

\author{
Humaira Asghar ${ }^{1} \cdot$ Muhammad Adeel lqbal $^{2} \cdot$ Muhammad Ahsan Iqbal $^{3}$ (D)
}

(c) Springer Nature Switzerland AG 2019

\begin{abstract}
In this contribution, new electrocatalyst materials, namely silicon-multiwalled carbon nanotubes (Si/MWCNTs), nitrogendoped multiwalled carbon nano-tubes (Si/NCNTs), and silicon-carbon black (Si/CB), were developed and characterized in an effort to investigate less expensive and more efficient alternatives to Pt-based catalysis for energy storage cells applications. The role of structural behavior of obtained specimens and corresponding electrochemical performances were characterized through $\mathrm{X}$-ray diffraction and scanning electron microscopy, while cyclic voltammetry and electrochemical impedance spectroscopy were analyzed for electrochemical measurements and evaluation of oxygen evolution reaction $(\mathrm{OER})$ along with oxygen reduction reaction (ORR). The electrochemical studies have shown that these materials exhibit reasonable performance for both the ORR and the OER. The findings concluded that the Si/CB base catalyst has shown both OER and ORR activities in comparison to Si/MWCNTs and Si/NCNTs where only ORR performance was monitored. However, Si/NCNTs have shown much higher ORR activity compared to the others. This work highlights the comparison of three possible alternative materials as a potential catalyst to develop optimum alternatives of Pt-free catalysts for fuel cell and lithium-based battery systems.
\end{abstract}

Keywords Electro-catalyst $\cdot$ Cyclic voltammetry $\cdot$ Electro-catalytic activity $\cdot$ OER $\cdot$ ORR

\section{Introduction}

One of the key challenges for the commercialization of electrochemical energy conversion and energy storage technologies is the development of low-cost and efficient electrocatalysts [1]. The electrochemical reactions play a vital role in the energy conversion process, for instance;-fuel cells, metal-air battery systems, water splitting-are oxygen reduction reactions (ORR) and oxygen evolution reactions (OER) $[2,3]$. The overall performances of those energy conversion systems are intensively limited due to sluggish kinetics in the evolution of molecular oxygen. The electrocatalytic reduction also has limitations [4-6], as it demands suitable development of bifunctional active electrocatalysts for both ORR and OER at the electrodes. In that aspect, various transition metal and noble metals catalysts- $\mathrm{Co}, \mathrm{Ni}$, $\mathrm{Mn}$, and Fe based-were widely employed for ORR and OER electrocatalysis [7-11]. Most recently, carbon-based metal-free nanostructured electrocatalysts, for example, graphene carbon-based nanotubes were investigated [12] and achieved valuable results for energy conversion and storage systems through different innovative ways, including geometric structuring, surface functionalization, and heteroatom doping [13-15]. Among them, nitrogen-doped carbon nanomaterials have received prominent attention as an efficient OER and ORR electrocatalyst due to their high catalytic activity towards

$\triangle$ Muhammad Ahsan Iqbal, muhammadahsan.iqbal@unitn.it | ${ }^{1}$ U.S. Pakistan Center for Advanced Studies in Energy (USPCAS-E), National University of Science and Technology (NUST), Islamabad 44000, Pakistan. ${ }^{2}$ Department of Mechanical and Aerospace Engineering, Air University Islamabad, Islamabad, Pakistan. ${ }^{3}$ Department of Industrial Engineering, University of Trento, Via Sommarive 9, 38123 Povo, TN, Italy.

SN Applied Sciences (2019) 1:1396 | https://doi.org/10.1007/s42452-019-1416-1

Received: 4 February 2019 / Accepted: 9 October 2019 / Published online: 14 October 2019

SN Applied Sciences

A SPRINGER NATURE journal 
$\mathrm{O}_{2}$ reduction [16-19]. Generally, $\mathrm{N}$-doping is preferred because of the closeness in size $(65 \mathrm{pm})$ of the $\mathrm{N}$ atom with that $(70 \mathrm{pm})$ of a carbon atom [20]. Therefore, several $\mathrm{N}$-doped cathode catalysts have been synthesized and used as the cathode of microbial fuel cells with increased efficiency [21-23].

In nitrogen-containing carbon material, it is believed that nitrogen is responsible for the enhanced ORR activity. These nitrogen functional groups transform into more thermally stable structures during heat treatment. Furthermore, nitrogen is known to be able to create defects on carbon, which may then increase the edge plane exposure and thus enhance the catalytic activity [24]. The fundamental investigation into these materials suggests that both the morphology and the surface play significant roles in their overall $\mathrm{O}_{2}$ activity.

It is also revealed in a number of studies that heteroatoms-codoped carbonaceous materials have shown a greater ORR activity compare to the unitary heteroatom doped materials $[25,26]$. Furthermore, heteroatom's doped carbon material also possesses the advantage of long-term stability along with high electrochemical performance. The heteroatom-doped carbon catalyst, in that scenario, can be studied further to address the issues of conventionally used platinum-based catalysts, including stability, poor ORR kinetics, platinum migration, agglomeration, high cost, etc. [25-28]. On parallel, polymermetallic based carbonaceous nanocomposites and further nitrogen-doped approach are used to improve microbial fuel cells exhibiting high electrochemical activity [29, 30]. Carbon nanotubes (CNTs) and Graphene (G), a promising class of carbon nanomaterials, have attracted considerable attention due to interesting electronic, photonic, and electrocatalytic characteristics, and are actively used in energy conversion and storage [31,32]. This provides a new window to develop and investigate new generations of graphene and promising CNT-based heterogeneous nitrogen-doped materials for energy conversion systems. In this study, we succeeded to develop Si-based composites with multiwall carbon nanotubes, nitrogen-doped carbon nanotubes, and carbon black, and these materials are investigated in an effort to increase the ORR and OER performances with excellent stability in alkaline media. To the best of our knowledge, Si-containing carbon materials with high ORR activity were scarcely investigated except the $\mathrm{Si}$ and $\mathrm{P}$ co-doped carbon. In particular, in this study, a comparative study is carried out by testing Si-based composites with multiwall carbon nanotubes, nitrogendoped carbon nanotubes, and carbon black through electrochemical impedance spectroscopy and cyclic voltammetry to analyze the difference in their performance. This work provides necessary highlights to the use of alternative catalysts.

\section{Experimental section}

\subsection{Materials}

The starting raw materials for electrode were commercially available powders of Silicon (Si) (99.9\% purity) (Fisher Scientific), Ammonium fluoride $\left(\mathrm{NH}_{4} \mathrm{~F}\right)$ (98\% Purity) (SigmaAldrich Inc), Multiwalled carbon nanotubes (MWCNTs) (Cheap Tubes Inc), nitrogen-doped multiwalled carbon nano-tubes (NCNTs) (Cheap Tubes Inc), Carbon black (Cheap Tubes Inc), Graphene oxide (GO) (Cheap Tubes Inc), and Ethyl alcohol $\left(\mathrm{C}_{2} \mathrm{H}_{5} \mathrm{OH}\right)$ (95\% purity) (BDH).

\subsection{Samples preparation}

Initially, silicon powder was ground into an agate with milling balls (Model: YLJ-24T, MTI Corporation) under $4000 \mathrm{RPM}$ for $4 \mathrm{~h}$ and further silicon powder $(1 \mathrm{~g})$, multiwall carbon nanotubes $(0.2 \mathrm{~g}), \mathrm{NH}_{4} \mathrm{~F}(1.2 \mathrm{~g})$ and ethyl alcohol $(5 \mathrm{ml})$ were milled and magnetically stirred for $24 \mathrm{~h}$ to form slurry (Fig. 1).

The resulted slurry was then calcined at $550{ }^{\circ} \mathrm{C}$ with $10^{\circ} \mathrm{C} /$ min heating rate for $5 \mathrm{~h}$ in a constant flow of inert gas (Argon atmospheric) using a tube furnace (Model: GSL-1800X-S60, MTI Corporation) to obtain silicon/MCNTs hybrids. For comparison, nitrogen-doped carbon nanotubes (Si/NCNTs) and Silicon/carbon black (Si/CB) were also synthesized by taking the same initial weight as for Si/MWCNTs composition and by following the above procedure. In summary, the silicon is ball milled with three different materials to prepare Si/MWCNTs, Si/NCNTs, and Si/CB separately.

\subsection{Physicochemical characterizations}

The morphology of the prepared materials is characterized by scanning electron microscopy (SEM) (Model: VEGA3, Tescan) at acceleration voltage $20 \mathrm{kV}$ and the phase identification, and a purity analysis was carried out by X-ray Diffractometer (XRD) (Model: D8 Advance, Bruker) using CuKa radiation $\left(\mathrm{k}=1.54051 \AA\right.$ ) with a step size of $0.01^{\circ}$.

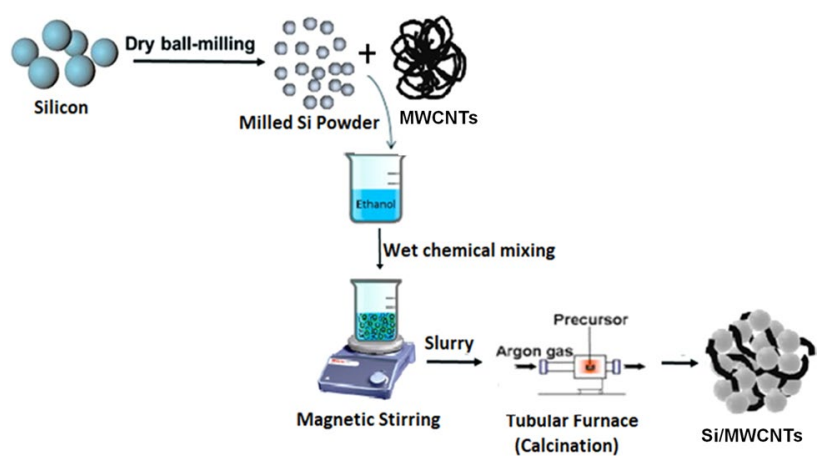

Fig. 1 Synthesis route of Si-MWCNTs carbonaceous material 


\subsection{Electrochemical characterizations}

All synthesized samples were tested for electrochemical measurements using a Gamry Interface 1000E Potentiostat Instrument. Glassy carbon electrode (GCE) $\left(7.065 \mathrm{~mm}^{2}\right)$, deposited with investigated material was consider as the working electrode, while $\mathrm{Ag} / \mathrm{AgCl}$ was used as a reference with platinum as a counter electrode. For electrochemical measurements, $100 \mu \mathrm{l}$ Ethanol with $20 \mu \mathrm{l}$ of ( $5 \mathrm{wt} \%$ ) Nafion was mixed thoroughly with the $2 \mathrm{mg}$ of each synthesized materials i.e., Si/MWCNTs, Si/NCNTs, and Si/CB. Then the $15 \mu \mathrm{l}$ resulted slurry was transferred on to a glassy carbon electrode ( $3 \mathrm{~mm}$ in diameter) using a micropipette, which further dried using a hot air blower. Ethanol was used as a solvent and ( $5 \mathrm{wt} \%$ ) Nafion solution was used as an electrolyte to provide sufficient conductivity and a binding agent. 0.1 $\mathrm{M} \mathrm{KOH}$ solution was used as a supporting electrolyte. Cyclic voltammetry was performed at different scan rates with a frequency range of $100 \mathrm{kHz}$ to $10 \mathrm{mHz}$ and $5 \mathrm{mV}$ amplitude. Electrochemical Impedance

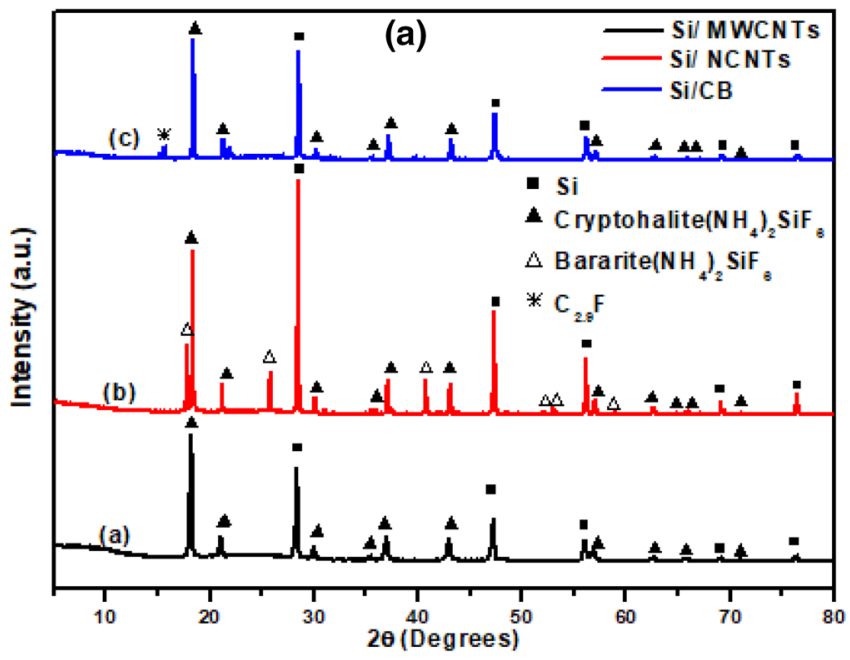

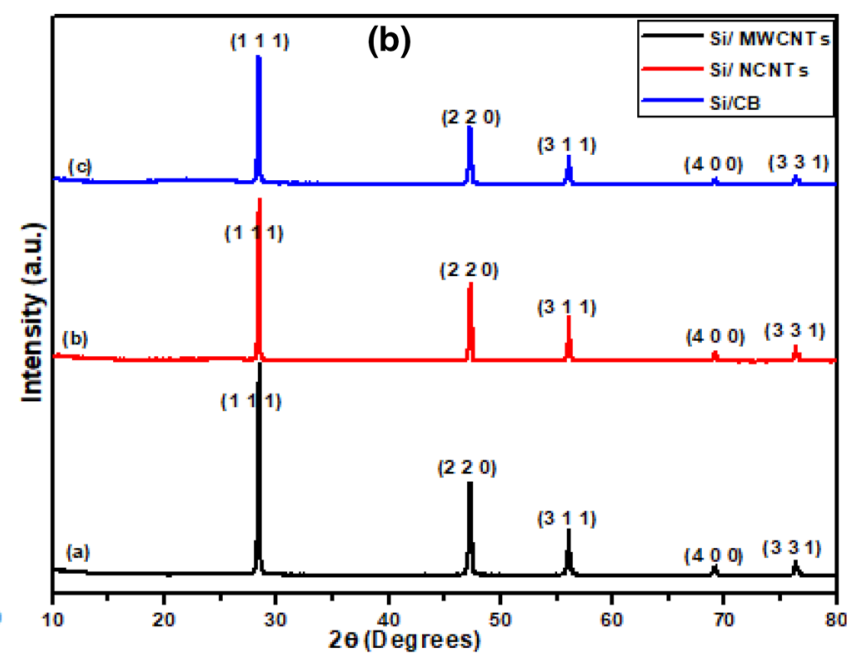

Spectroscopy (EIS) was performed using the same threeelectrode setup.

\section{Results and discussions}

The XRD analysis of silicon with different forms of carbon is displayed in Fig. 2a-c. The pulverized silicon reacts gradually with ammonium fluoride and forms different metastable phases like silicon fluorides and ammonium fluorides during the stirring process, which causes the reduction of silicon particle size. Subsequently, after the calcination at $550^{\circ} \mathrm{C}$ temperature for $5 \mathrm{~h}$, the obtained fluorides decompose and volatize, and absolute purity is achieved in the diffraction patterns of Si/MWCNTs, Si/NCNTs, and $\mathrm{Si} / \mathrm{CB}$ (Fig. 2b). The pattern of composites is the same as that of pure Si nanoparticles as validated through JCPDS card no. 27-1402, implying that the silicon crystals in the composites are not annihilated during the processing. It can be observed that the silicon main diffraction peaks

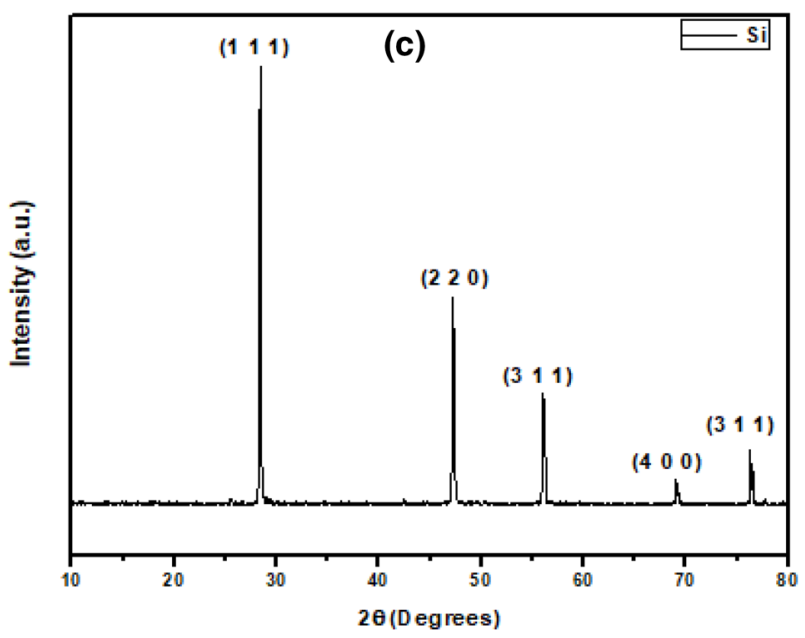

Fig. 2 XRD comparison pattern of a before calcinations, $\mathbf{b}$ after calcinations, $\mathbf{c}$ silicon pattern for comparison 
show the presence of pristine silicon, with a major decline in peak intensity, which ensures homogeneous mixing as well as homogeneous incorporation of silicon in the carbon network. For comparison purpose, the XRD pattern of pure silicon is also shown in Fig. 2c. The XRD of uncalcined $\mathrm{Si} / \mathrm{MWCNTs}$, Si/NCNTs/Si/CB is also represented in Fig. 2 a. When Si reacts with carbon it forms different metastable phases that are hydrolysis products of $\mathrm{Si}$, ammonium fluoride and carbon. On heat treatment of the samples, metastable phases decompose or volatize and homogenous $\mathrm{Si} / \mathrm{C}$ composites form that is the reason that composites have shown the almost same XRD pattern as of Si and at $550^{\circ} \mathrm{C}$, the peak intensity of carbon becomes negligible due to high dominancy of high silicon peak intensity.

Figure 3 shows the morphological analysis of Si/MWCNTs, Si/NCNTs, and Si/CB composite materials after calcination at $550^{\circ} \mathrm{C}$. As seen in low magnification images in
Fig. 3a, c, e, the carbon and silicon distributed on the surface of the Si-based carbonaceous composite materials. High magnification images in Fig. $3 b, d$, $f$ provide an idea of the silicon composites with carbonaceous materials particles, where Si and Carbon, MWCNTs are observed to be settled; and silicon particles appear to be coated on the MWCNTs, which is also confirmed in other works [33]. That trend is much evident in XRD patterns, as silicon structure indicates lattice strain with MWCNTs, so it is possible to say lattice parameter of silicon particles change and coat on MWCNTs surface [33]. That specific surface area of the carbon support has been proven to be a crucial factor in the catalytic activity. These properties of the materials will favor the ORR/OER performance for catalytic activities.

For the evaluation of oxygen evolution reaction (OER) and oxygen reduction reaction (ORR) performance of different samples, electrodes were prepared and linear
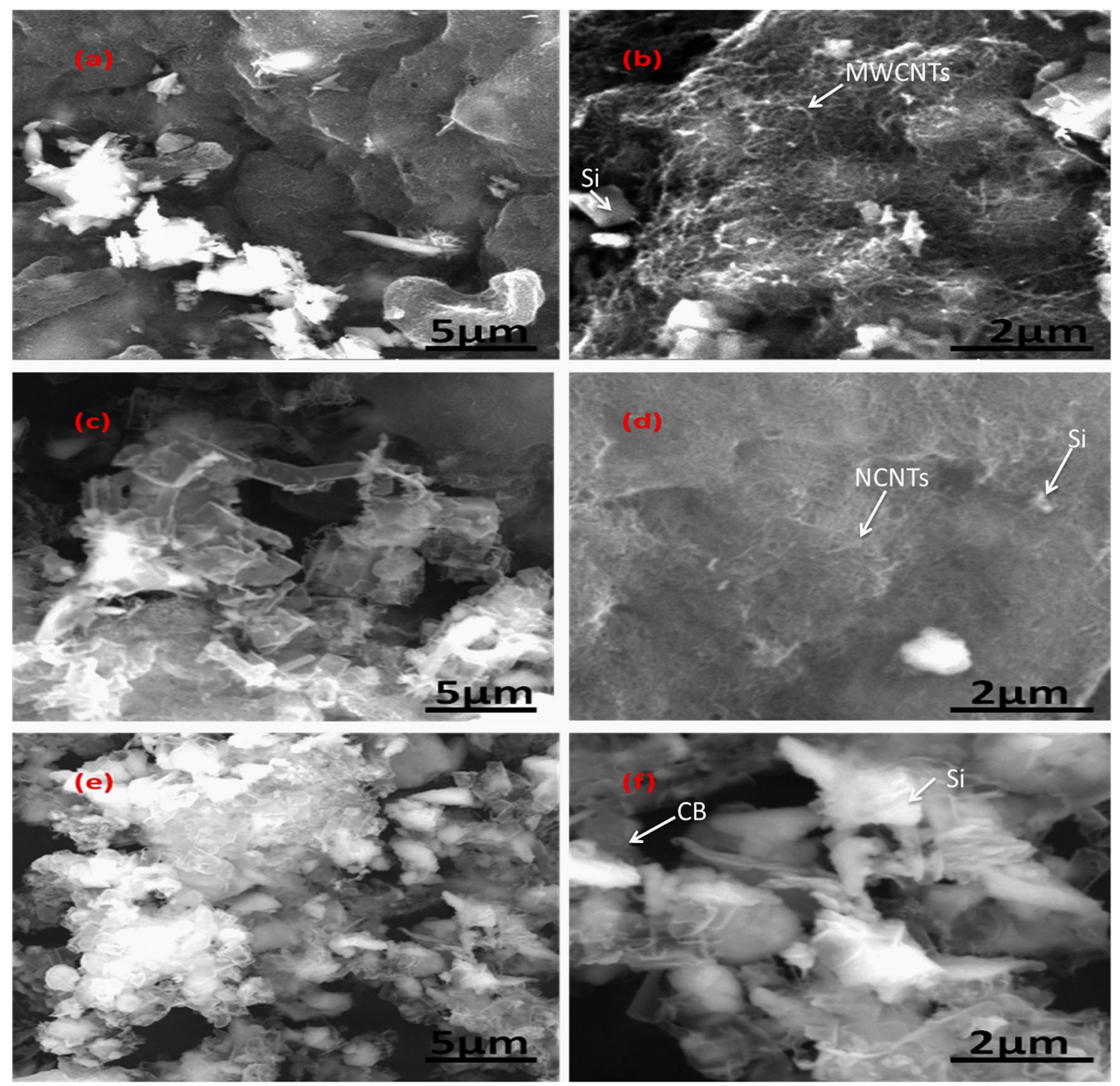

Fig. 3 SEM images of a, b Si/MWCNTs, $\mathbf{c}, \mathbf{d}$ Si/NCNTs, e, $\mathbf{f} \mathrm{Si} / \mathrm{CB}$ at low and high magnifications respectively

SN Applied Sciences

A SPRINGER NATURE journal 
sweep voltammetry (LSV) and cyclic voltammetry (CV) were performed in a three-electrode assembly in $0.1 \mathrm{M}$ $\mathrm{KOH}$ solution as a supporting electrolyte. Figure $4 \mathrm{a}$ showed the comparison of three different samples on the basis of linear sweep voltammetry. As evident from the voltammogram, the Si/NCNTs had the highest current density at higher onset potential. Figure $4 \mathrm{~b}$ shows the recorded voltammogram for the Si/MWCNTs, Si/ NCNTs, and Si/Carbon black at the scan rate of $100 \mathrm{mV} / \mathrm{s}$ at room temperature. Si/MWCNTs shows only a distinctive (ORR) cathodic peak at $-0.55 \mathrm{~V}$ with the current density of $8.56 \mathrm{~mA} / \mathrm{cm}^{2}$, and the ORR peak with $12 \mathrm{~mA} /$ $\mathrm{cm}^{2}$ current density appeared for $\mathrm{Si} / \mathrm{N}_{2}$-doped CNTs at a voltage of $-0.49 \mathrm{~V}$. The manifest improvement of ORR potential and peak current density of Si/NCNTs indicate the additional doping of nitrogen could improve the ORR activity of carbon materials. The boosted performance of the Si/NCNTs was also supported by LSV measurements. The $\mathrm{Si} / \mathrm{CB}$ material shows both ORR and OER peaks. Oxygen-reduction peak appears at $0.46 \mathrm{~V}$ and OER peak at $1.47 \mathrm{~V}$ with peak current densities of $0.347 \mathrm{~mA} /$ $\mathrm{cm}^{2}$ and $6.79 \mathrm{~mA} / \mathrm{cm}^{2}$ respectively. Onset potential, peak potential, and the peak current densities were measured and compared in Table 1.

From the comparison in Table 1, we can say that the Si/ NCNTs offer highest peak current density in comparison

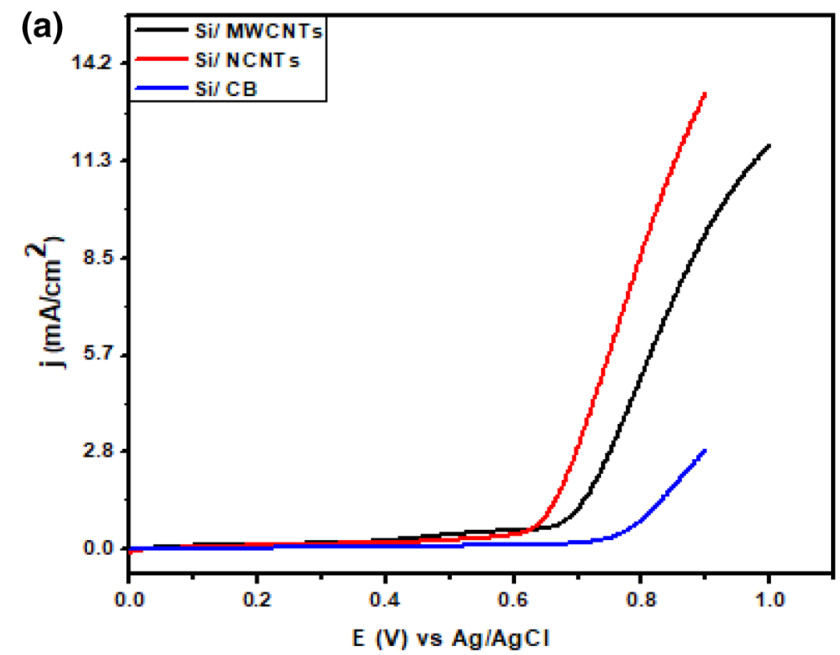

to the other two prepared materials, yet, at the same time, the $\mathrm{Si} / \mathrm{CB}$ material show the ORR potential in addition to the OER potential. It is unconcealed from Table 1 that the onset potential of Si/NCNTs at $0.11 \mathrm{~V}$ is visibly higher than that of Si/MCNTs at $-0.175 \mathrm{~V}$, as is the case with current densities. It is quite evident that the doping of $\mathrm{Si}$ and nitrogen into carbon networks can possibly lead to significant improvements in electrochemical performance.

The purging of the solution or the electrolyte was carried out with an inert gas in different time intervals to confirm that no other analyte is present in the electrolyte and only dissolved oxygen reacts with the electrode. The voltammograms were recorded with a 10 min purge of argon gas and compared the response with dissolved oxygen as shown in Fig. 5a, b, c for Si-MCNTs, Si/NCNT, and Si/CB respectively. The specified pattern demonstrates a slight change in peaks, validating the presence of dissolved oxygen as the only analyte present in the supporting electrolyte.

Figure $5 d, e, f$ depicts the $C V$ response at different scan rates- $50 \mathrm{mV} / \mathrm{s}, 100 \mathrm{mV} / \mathrm{s}$, and $150 \mathrm{mV} / \mathrm{s}$-for Si/MWCNTs, $\mathrm{Si} / \mathrm{NCNTs}$ and Si/CB over the peak current density. CV $100 \mathrm{mV}$ is found the most used scan rate for such type of materials, thus authors follow the same scan rate to follow the other literature studies [34]. It can be seen clearly that all materials show stable responses against increasing scan rates and the peak current densities of composites increase with an

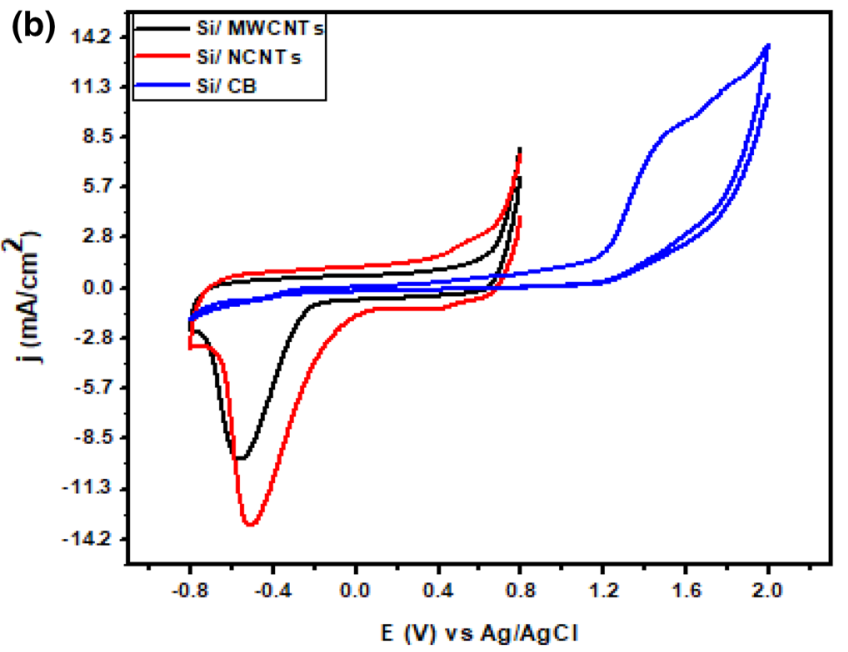

Fig. 4 a LSV and b CV curves at $100 \mathrm{mV} / \mathrm{s}$ for Si/MWCNTs, Si/NCNTs, and Si/CB

Table 1 Onset potential, peak potential and peak current of Si-based carbonaceous materials

\begin{tabular}{|c|c|c|c|c|c|c|}
\hline \multirow[t]{2}{*}{ Samples } & \multicolumn{2}{|c|}{$\begin{array}{l}\text { Onset potential versus } \mathrm{Ag} / \\
\mathrm{AgCl}(\mathrm{V})\end{array}$} & \multicolumn{2}{|c|}{$\begin{array}{l}\text { Peak potential versus } \mathrm{Ag} / \\
\mathrm{AgCl}(\mathrm{V})\end{array}$} & \multicolumn{2}{|c|}{$\begin{array}{l}\text { Peak current den- } \\
\text { sity }\left(\mathrm{mA} / \mathrm{cm}^{2}\right)\end{array}$} \\
\hline & OER & ORR & OER & ORR & OER & ORR \\
\hline Si/MWCNTs & - & -0.175 & - & -0.559 & - & 8.56 \\
\hline Si/NCNTs & - & 0.11 & - & -0.49 & - & 12 \\
\hline $\mathrm{Si} / \mathrm{CB}$ & 1.083 & -0.29 & 1.47 & -0.46 & 6.79 & 0.34 \\
\hline
\end{tabular}



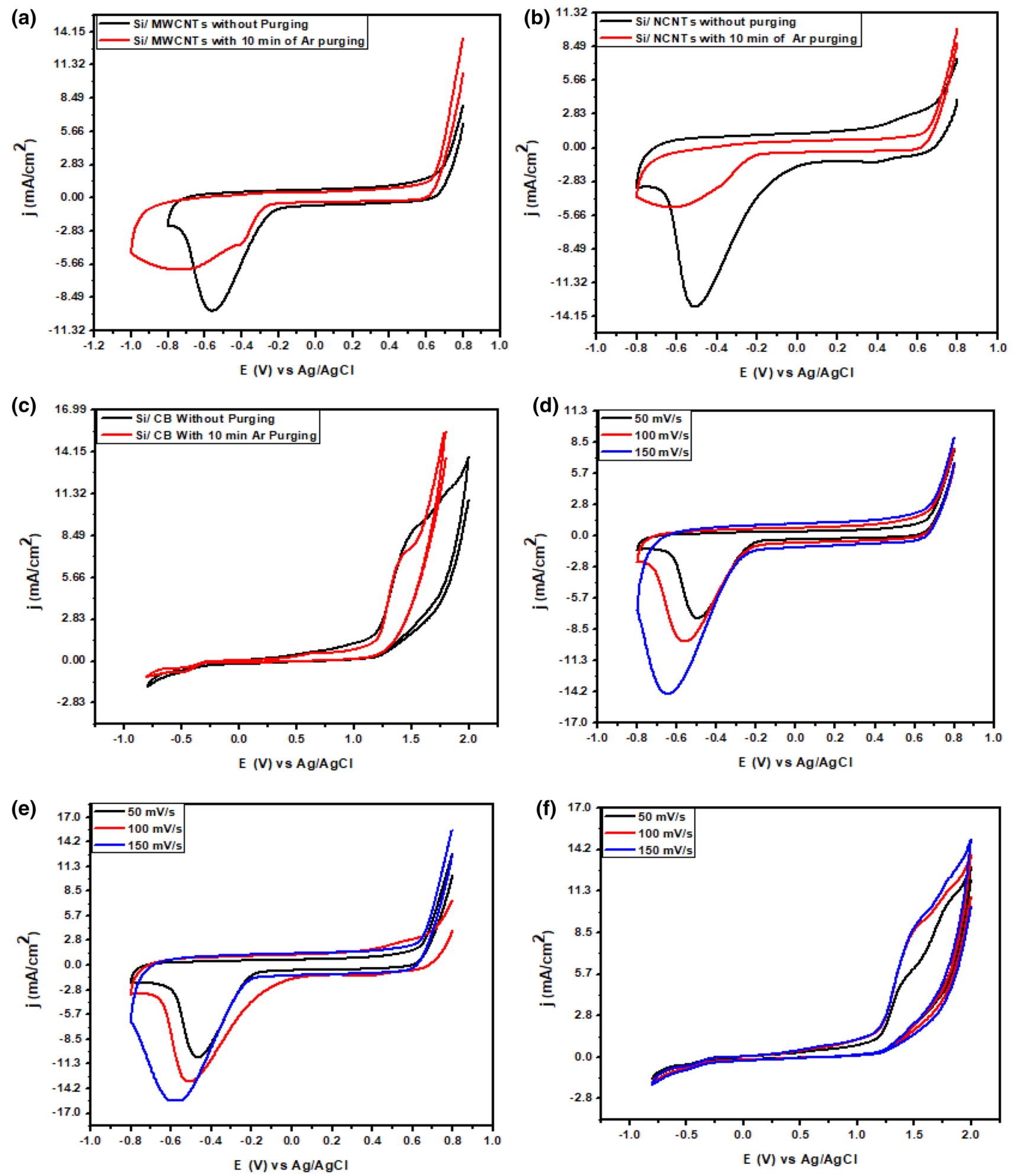

Fig. 5 CV curves with or without Ar gas purging for a Si/MWCNTs, b Si/NCNTs, and c Si/CB and CV curves at different scan rates for d Si/ MWCNTs, e Si/NCNTs, and $\mathbf{f} \mathrm{Si} / \mathrm{CB}$ 
increasing scan rate, showing that the peak current densities are linearly proportional to the root of sweep rates. The voltammograms show that with increasing scan rates, peaks become more prominent due to the fact that the faster scan rate doesn't permit the constituent of a reaction, which is not electroactive, to be reduced or oxidized into the products. Such is why the peak current densities are higher at higher scan rates.

As shown in Fig. 6, a linear trend between peak current densities and the square root of scan rate for each material, which indicates the possibility of a diffusion controlled process. The experimental points are connected to three different scan rates $(50,100,150150 \mathrm{mV} / \mathrm{s})$ with the under root values of 7,10 and $12 \mathrm{mV} / \mathrm{s}$, which were plotted against their respective peak current densities to find out the average peak current density of each material (calculated by the slope of respective line), and further used for determining the diffusion coefficient of each material through Randles-Sevcik equation (Eq. 1)

Ip $=0.4463 n F A C \sqrt{\frac{n F v D}{R T}}$

where $i_{p}=$ Peak Current density, $\mathrm{n}=$ No. of electron transfer, $D=$ Diffusion coefficients, $A=$ Surface area of $G C E, C=$ Bulk conc. of analyte in supporting electrolyte and $v=S c a n$ rate, $\mathrm{R}=$ General gas constant and $\mathrm{T}=$ Room temperature. It is also be seen the two Si/CB lines in Fig. 6, in CV measurements, if there are two peaks appear in the response of the material then it's mean that material is showing

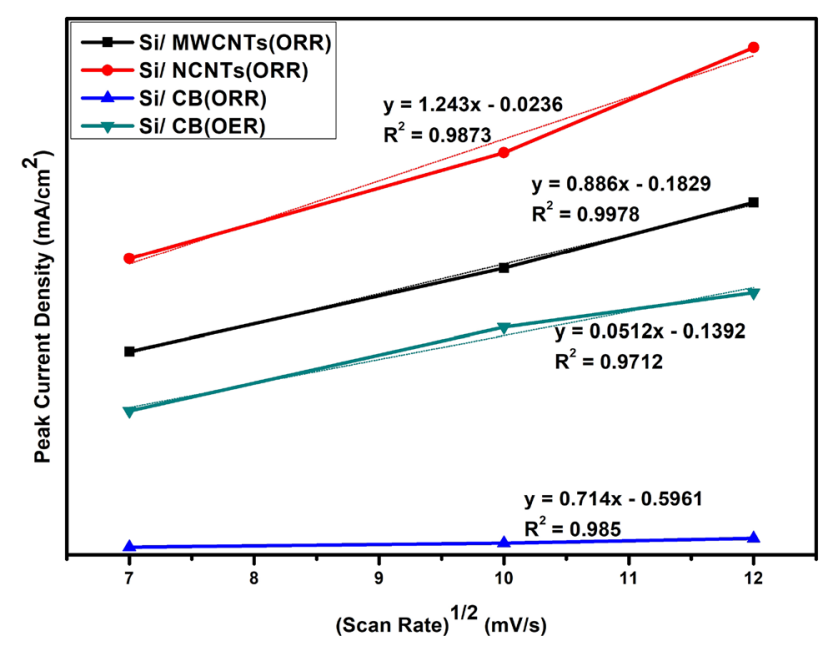

Fig. 6 Graph of the square root of scan rate versus current Si/MWCNTs, Si/NCNTs, Si/CB — anodic and Si/CB — cathodic currents density both anodic and cathodic currents that are a property of bifunctional material. Here, Si/CB has shown both oxygen reduction and oxygen evolution reactions. So one line was for anodic current and the other was showing cathodic current.

Furthermore, Tafel plots between over-potential and current densities were made for measuring exchange current densities, as shown in Fig. 7. Electrochemical kinetics is explained by Tafel plots by comparing current density and overpotential. It shows in what manner overp otential has to be increased to escalate the reaction kinetics. The better value of overpotential depicts that the material requires less activation energy and is catalytically more active. Diffusion coefficients and exchange current densities of the prepared materials were recorded and compared in Table 2.

To understand the characteristics of the prepared materials in a more detailed way, electrochemical impedance spectroscopy was performed for the prepared different materials using the same three-electrode system in $0.1 \mathrm{M}$ $\mathrm{KOH}$ solution under potentiostatic mode. It is evident from the Nyquist plot (Fig. 8) that, the curves bend shifted right and responds to changes with changing forms of the carbon. For the Si/CB and Si/NCNT samples, there is a substantial decrease in impedance, which is, in fact, the reduction in impedance for the electron transfer process $[31,35]$. The size of the Nyquist semicircle considerably decreased for the $\mathrm{Si} / \mathrm{CB}$ because of the decrease in charge transfer resistance, attributed to the high kinetic rate and also due to the relatively high conductive surface which proved to be responsible for the high charge transfer rate [36]. The diameter of the curve for Si/NCNT and Si/CB is seemed to be smaller than that of Si/MWCNT, and thus demonstrate superior charge transport kinetics naturally, this is in accordance with the above explanation and previous studies [37]. Due to the reduction in charge transfer resistance, surface area and conductivities of electrodes increase. Furthermore, higher homogeneity in $\mathrm{Si} / \mathrm{CB}$ and $\mathrm{Si} / \mathrm{NCNT}$ is reflected by a systematized behavior of the $\mathrm{Si} /$ $\mathrm{CB}$ and $\mathrm{Si} / \mathrm{NCNT}$, in comparison to Si/MCNTs as per witnessed from the capacitive current performance in voltammetric studies (Fig. 5). Further, it can conclude that as the impedance of $\mathrm{Si} / \mathrm{CB}$ and $\mathrm{Si} / \mathrm{NCNTs}$ is way less than that in the Si/MWCNTs, This significant reduction in charge transfer resistance clearly favors ORR and OER reactions in $\mathrm{Si} / \mathrm{CB}$ case, while ORR in Si/NCNTs as compared to Si/MWCNTs. In a nutshell, the impedance results are strongly in concordance with the voltammetry findings drawn above. 

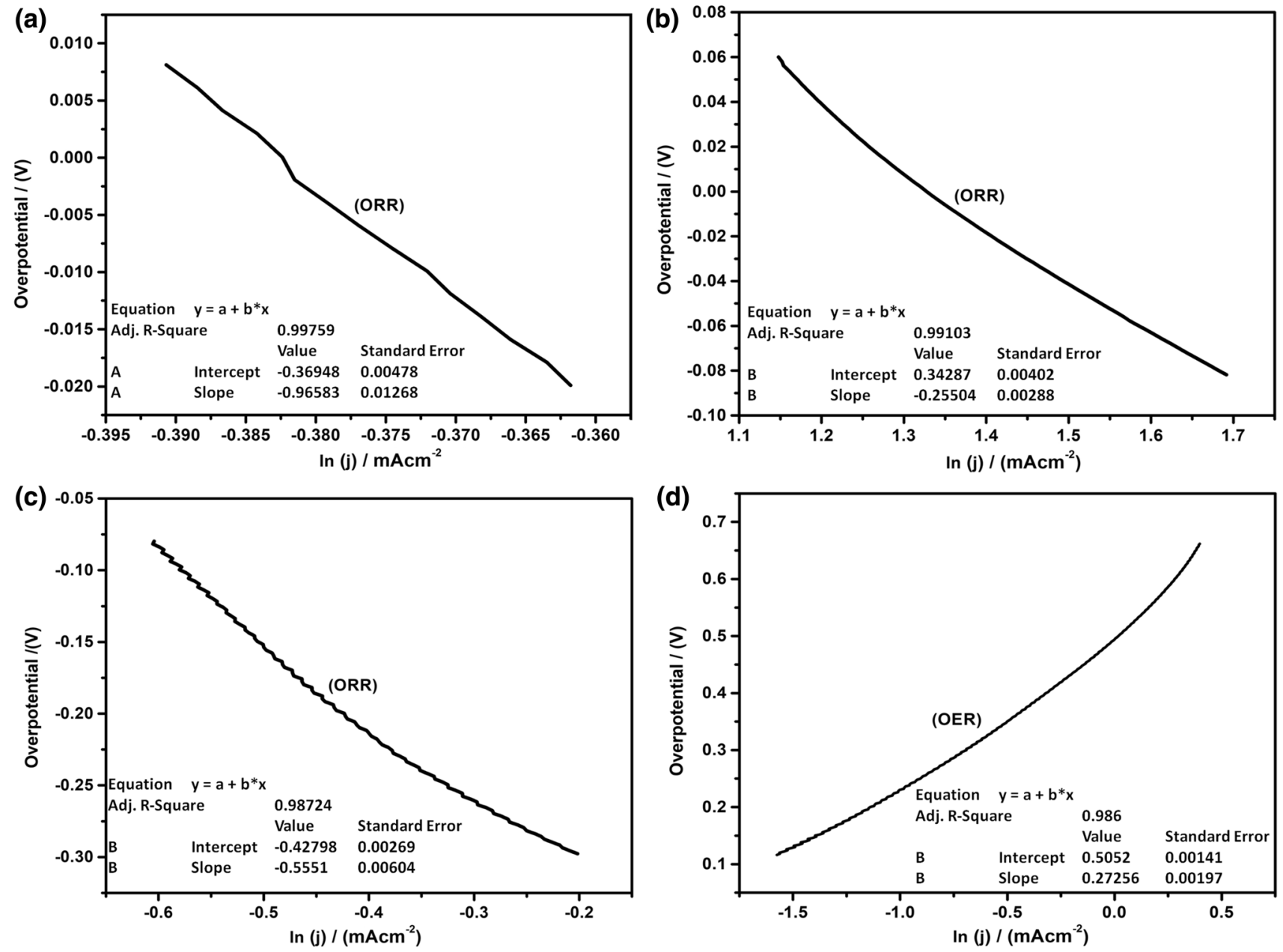

Fig. 7 Tafel plots for a Si/MWCNTs, b Si/NCNTs, and c, d Si/CB

Table 2 Diffusion coefficients and exchange current density of carbonaceous materials

\begin{tabular}{lcl}
\hline Type of material & $\begin{array}{l}\text { Diffusion coefficients } \\
(\mathrm{D})\left(\mathrm{cm}^{2} / \mathrm{s}\right)\end{array}$ & $\begin{array}{l}\text { Exchange current } \\
\text { density }\left(\mathrm{j}^{0}\right)(\mathrm{mA} / \\
\left.\mathrm{cm}^{2}\right)\end{array}$ \\
\hline $\mathrm{Si} / \mathrm{MWCNTs}_{\mathrm{ORR}}$ & $7.55 \times 10^{-5}$ & 0.68 \\
$\mathrm{Si} / \mathrm{NCNTs}_{\mathrm{ORR}}$ & $1.5 \times 10^{-4}$ & 3.8 \\
$\mathrm{Si} / \mathrm{CB}_{\text {ORR }}$ & $4.9 \times 10^{-5}$ & 0.46 \\
$\mathrm{Si} / \mathrm{CB}_{\mathrm{OER}}$ & $2.5 \times 10^{-7}$ & 0.15 \\
\hline
\end{tabular}

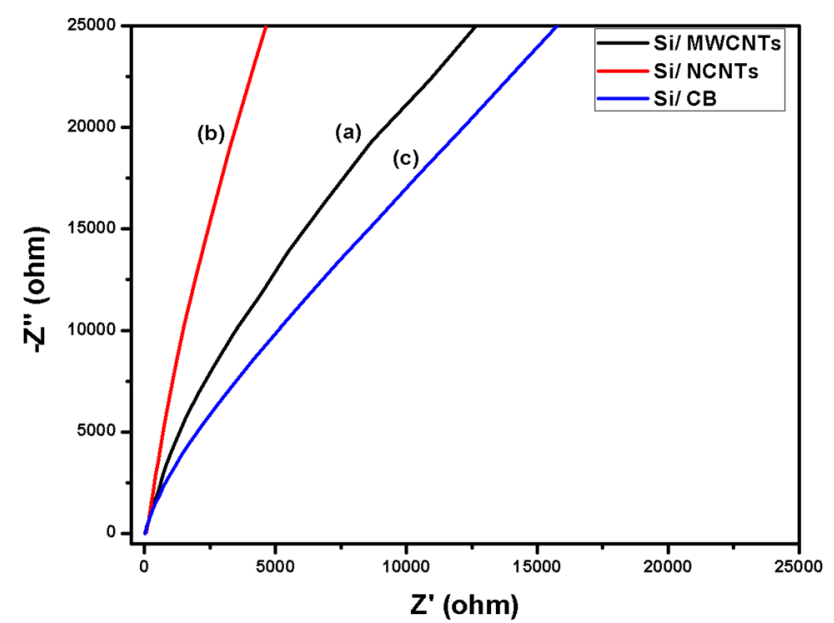

Fig. 8 EIS Nyquist plot of a Si/MWCNTs, b Si/NCNTs, and c Si/CB 


\section{Conclusion}

In this work, Si-based composites are synthesized, by high energy ball-milling, with multiwall carbon nanotubes, nitrogen-doped carbon nanotubes, and carbon black in an effort to increase the ORR and OER performances of the silicon composites. SEM analysis has shown the surface morphologies and distribution of Si within the carbon matrix, and further the cyclic voltammetry results suggested that the materials Si/MWCNTs and Si/NCNTs can be used as a catalyst for achieving higher reduction properties, whereas $\mathrm{Si} / \mathrm{CB}$ has shown both oxidation/reduction properties and thus act as a bifunctional catalyst for ORR and OER activities, while Si/NCNTs offer higher peak current density in comparison to the other investigated materials Nyquist plots impedance results also to be in concordance with the voltammetry findings and help to understand the electrochemical response. We expect that these types of Si-containing carbon materials could be served as low-cost efficient ORR catalysts and the doping of silicon could be investigated to design much lower-cost and more efficient metal-free electrocatalysts for the ORR in the future alkaline fuel cell devices.

Acknowledgements The authors are immensely grateful to USAID, NUST PGP Directorate, and Quaid-e-Azam University, Islamabad (Department of Physical Chemistry) for providing technical support to carry out this research work.

\section{Compliance with ethical standards}

Conflict of interest The authors declare no conflict of interest.

\section{References}

1. Wang DW, Su D (2014) Heterogeneous nanocarbon materials for the oxygen reduction reaction. Energy Environ Sci 7(2):576-591

2. Jörissen $L$ (2006) Bifunctional oxygen/air electrodes. J Power Sources 155(1):23-32

3. Pettersson J, Ramsey B, Harrison D (2006) A review of the latest developments in electrodes for unitised regenerative polymer electrolyte fuel cells. J Power Sources 157(1):28-34

4. Debe MK (2012) Electrocatalyst approaches and challenges for automotive fuel cells. Nature 486(7401):43

5. Piana M, Catanorchi S, Gasteiger HA (2008) Kinetics of non-platinum group metal catalysts for the oxygen reduction reaction in alkaline medium. ECS Trans 16(2):2045-2055

6. Cook TR, Dogutan DK, Reece SY, Surendranath Y, Teets TS, Nocera DG (2010) Solar energy supply and storage for the legacy and nonlegacy worlds. Chem Rev 110(11):6474-6502

7. Jiao Y, Zheng Y, Jaroniec M, Qiao SZ (2015) Design of electrocatalysts for oxygen-and hydrogen-involving energy conversion reactions. Chem Soc Rev 44(8):2060-2086

8. Duan J, Chen S, Jaroniec M, Qiao SZ (2015) Heteroatom-doped graphene-based materials for energy-relevant electrocatalytic processes. ACS Catal 5(9):5207-5234
9. Stamenkovic VR, Fowler B, Mun BS, Wang G, Ross PN, Lucas CA, Marković NM (2007) Improved oxygen reduction activity on Pt3Ni (111) via increased surface site availability. Science 315(5811):493-497

10. Chen C, Kang Y, Huo Z, Zhu Z, Huang W, Xin HL, Chi M (2014) Highly crystalline multimetallic nanoframes with three-dimensional electrocatalytic surfaces. Science 343(6177):1339-1343

11. Lee Y, Suntivich J, May KJ, Perry EE, Shao-Horn Y (2012) Synthesis and activities of rutile $\mathrm{IrO}_{2}$ and $\mathrm{RuO}_{2}$ nanoparticles for oxygen evolution in acid and alkaline solutions. J Phys Chem Lett 3(3):399-404

12. Li Q, Cao R, Cho J, Wu G (2014) Nanocarbon electrocatalysts for oxygen reduction in alkaline media for advanced energy conversion and storage. Adv Energy Mater 4(6):1301415

13. Steenackers M, Gigler AM, Zhang N, Deubel F, Seifert M, Hess LH, Stutzmann M (2011) Polymer brushes on graphene. J Am Chem Soc 133(27):10490-10498

14. Jiao L, Wang X, Diankov G, Wang H, Dai H (2010) Facile synthesis of high-quality graphene nanoribbons. Nat Nanotechnol 5(5):321

15. Li XH, Antonietti M (2013) Polycondensation of boron-and nitrogen-codoped holey graphene monoliths from molecules: carbocatalysts for selective oxidation. Angew Chemie 125(17):4670-4674

16. Liang J, Jiao Y, Jaroniec M, Qiao SZ (2012) Sulfur and nitrogen dual-doped mesoporous graphene electrocatalyst for oxygen reduction with synergistically enhanced performance. Angew Chemie 124(46):11664-11668

17. Ma Z, Dou S, Shen A, Tao L, Dai L, Wang S (2015) Sulfur-doped graphene derived from cycled lithium-sulfur batteries as a metal-free electrocatalyst for the oxygen reduction reaction. Angew Chemie Int Ed 54(6):1888-1892

18. Lu X, Yim WL, Suryanto BH, Zhao C (2015) Electrocatalytic oxygen evolution at surface-oxidized multiwall carbon nanotubes. J Am Chem Soc 137(8):2901-2907

19. Zhao $Y$, Nakamura R, Kamiya K, Nakanishi S, Hashimoto $K$ (2013) Nitrogen-doped carbon nanomaterials as non-metal electrocatalysts for water oxidation. Nat Commun 4:2390

20. Shui J, Wang M, Du F, Dai L (2015) N-doped carbon nanomaterials are durable catalysts for oxygen reduction reaction in acidic fuel cells. Sci Adv 1:e1400129

21. Qu L, Liu Y, Baek J-B, Dai L (2010) Nitrogen-doped graphene as efficient metal-free electrocatalyst for oxygen reduction in fuel cells. ACS Nano 4:1321e6

22. Feng $L$, Yan $Y$, Chen $Y$, Wang $L$ (2011) Nitrogen-doped carbon nanotubes as efficient and durable metal-free cathodic catalysts for oxygen reduction in microbial fuel cells. Energy Environ Sci 4:1892e9

23. Feng L, Yang L, Huang Z, Luo J, Li M, Wang D et al (2013) Enhancing electrocatalytic oxygen reduction on nitrogendoped graphene by active sites implantation. Sci Rep 3:3306

24. Nagaiah Tharamani C, Kundu Shankhamala, Bron Michael et al (2010) Nitrogen-doped carbon nanotubes as a cathode catalyst for the oxygen reduction reaction in alkaline medium. Electrochem Commun 12:338-341. https://doi.org/10.1016/j. elecom.2009.12.021

25. Nasini UB, Gopal Bairi V, Kumar Ramasahayam S, Bourdo SE, Viswanathan T, Shaikh AU (2014) Oxygen reduction reaction studies of phosphorus and nitrogen co-doped mesoporous carbon synthesized via microwave technique. ChemElectroChem 1(3):573-579

26. Kong XK, Chen CL, Chen QW (2014) Doped graphene for metal-free catalysis. Chem Soc Rev 43(8):2841-2857

27. Razmjooei F, Singh KP, Song MY, Yu JS (2014) Enhanced electrocatalytic activity due to additional phosphorous doping in 
nitrogen and sulfur-doped graphene: a comprehensive study. Carbon 78:257-267

28. Ramasahayam SK, Nasini UB, Bairi V, Shaikh AU, Viswanathan $\mathrm{T}$ (2014) Microwave assisted synthesis and characterization of silicon and phosphorous co-doped carbon as an electrocatalyst for oxygen reduction reaction. RSC Adv 4(12):6306-6313

29. Bairi VG, Bourdo SE, Nasini UB, Ramasahayam SK, Watanabe F, Berry BC, Viswanathan T (2013) Microwave-assisted synthesis of nitrogen and phosphorus co-doped mesoporous carbon and their potential application in alkaline fuel cells. Sci Adv Mater 5(9):1275-1281

30. Modi A, Singh S, Verma N (2017) Improved performance of a single chamber microbial fuel cell using nitrogen-doped polymer-metal-carbon nanocomposite-based air-cathode. Int J Hydrog Energy 42(5):3271-3280

31. Singh S, Modi A, Verma N (2016) Enhanced power generation using a novel polymer-coated nanoparticles dispersedcarbon micro-nanofibers-based air-cathode in a membraneless single chamber microbial fuel cell. Int J Hydrog Energy 41(2):1237-1247

32. Wang S, Yu D, Dai L, Chang DW, Baek JB (2011) Polyelectrolytefunctionalized graphene as metal-free electrocatalysts for oxygen reduction. ACS Nano 5(8):6202-6209

33. Cetinkaya T, Tocoglu U, Cevher O, Guler MO, Akbulut H (2013) Preparation and characterisation of silicon/carbon nanotube composite electrodes for Li-ion battery systems. Acta Phys Pol, A 123(2):398-400

34. Huang ZD, Zhang $K$, Zhang TT, Liu RQ, Lin XJ, Li Y, Feng XM, Mei QB, Masese T, Ma YW, Huang W (2016) Binder-free graphene/ carbon nanotube/silicon hybrid grid as freestanding anode for high capacity lithium ion batteries. Compos Part A Appl Sci Manuf 84:386-392

35. Singh S, Verma N (2015) Graphitic carbon micronanofibers asymmetrically dispersed with alumina-nickel nanoparticles: a novel electrode for mediatorless microbial fuel cells. Int J Hydrog Energy 40(17):5928-5938

36. Lv Z, Xie D, Yue X, Feng C, Wei C (2012) Ruthenium oxide-coated carbon felt electrode: a highly active anode for microbial fuel cell applications. J Power Sources 210:26-31

37. Barral G, Maximovitch S, Njanjo-Eyoke F (1996) Study of electrochemically formed $\mathrm{Ni}(\mathrm{OH})_{2}$ layers by EIS. Electrochim Acta 41(7-8):1305-1311

Publisher's Note Springer Nature remains neutral with regard to jurisdictional claims in published maps and institutional affiliations. 